\title{
Clinical profile and outcome of organophosphorus poisoning in a tertiary care centre, a prospective observational study
}

\author{
Gagarin P. ${ }^{1}$, Rajagopal R. ${ }^{2 *}$
}

DOI: https://doi.org/10.17511/ijmrr.2020.i02.02

\footnotetext{
1 P. Yuri Gagarin, Associate professor, Department of General Medicine, Velammal Medical College Hospital and Research Institute, Madurai, Tamil Nadu, India.

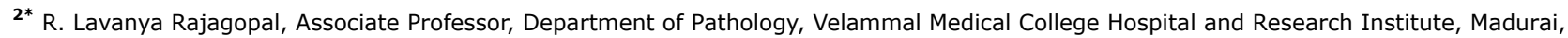
Tamil Nadu, India.
}

Introduction: Acute organophosphorus (OP) pesticide poisoning is widespread in the developing world. Being predominantly an agricultural country, pesticides and insecticides are used abundantly for cultivation, and access to these poisonous chemical substances by the population is easy. The objectiveof the study was to identifythe nature of the demographic profile, type of compound, clinical manifestations, and outcome of organophosphate poisoning presenting to a tertiary care teaching hospital in India. Material and methods: A cross-sectional study was conducted among 100 patients admitted with OPC poisoning inthe department of general medicine,Velammal Medical College Hospital and Research Institute, Madurai from January 2016 to July 2019. The diagnosis was made based on history or evidence of exposure to OP compound within 24 hours; characteristic manifestations of OP poisoning include, miosis, fasciculations, excessive salivation, improvement of signs and symptoms with administration of atropine were recorded. IBM SPSS version 22 was used for statistical analysis. Results:The majority of the subjects were males $(80 \%)$. The majority $(66 \%)$ were in the age group of 21-40 years. The most common OPC to be consumed was Methyl parathion $(27 \%)$, followed by chlorpyrifos $(22 \%)$. The major GIT complications were abdominal pain/cramps $(100 \%)$, followed by nausea and vomiting $(83 \%)$. Mechanical ventilation was needed in $40 \%$ and mortality was reported in $25 \%$ of the subjects. Conclusion:OP poisoning affects resonantly males in their economically productive phase of life. Considering the high mortality, adequate strengthening of health services, especially at the primary level is the need of the hour.

Keywords: Organophosphorus, Pesticides, Muscarinic manifestations, Nicotinic manifestations, Poisoning

\section{Corresponding Author}

R. Lavanya Rajagopal, Associate Professor, Department of Pathology, Velammal Medical College Hospital and Research Institute, Madurai, Tamil Nadu, India.

Email: drrlavan@yahoo.co.in
How to Cite this Article

To Browse

Gagarin PY, Rajagopal RL. Clinical profile and outcome of organophosphorus poisoning in a tertiary care centre, a prospective observational study. Int J Med Res Rev. 2020;8(2):148-153.

Available From

https://ijmrr.medresearch.in/index.php/ijmrr/article/ view/1156

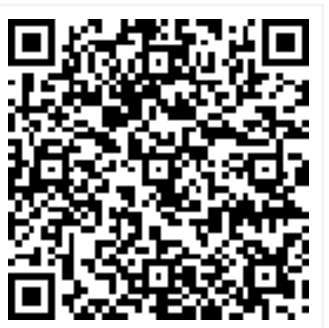

\begin{tabular}{|c|c|c|c|c|c|}
\hline \multicolumn{2}{|r|}{$\begin{array}{c}\text { Manuscript Received } \\
2020-02-25\end{array}$} & $\begin{array}{c}\text { Review Round } 1 \\
2020-03-07\end{array}$ & $\begin{array}{c}\text { Review Round } 2 \\
2020-03-12\end{array}$ & Review Round 3 & $\begin{array}{c}\text { Accepted } \\
2020-03-17\end{array}$ \\
\hline & $\begin{array}{l}\text { Conflict of Interest } \\
\text { No }\end{array}$ & $\begin{array}{c}\text { Funding } \\
\mathrm{Nil}\end{array}$ & $\begin{array}{c}\text { Ethical Approval } \\
\text { Yes }\end{array}$ & $\begin{array}{c}\text { Plagiarism X-checker } \\
8 \%\end{array}$ & Note \\
\hline OPEN & $\begin{array}{l}\text { (C) } 2020 \text { by } \\
\text { ACCESS }\end{array}$ & $\begin{array}{l}\text { R. Lavanya Rajago } \\
\text { cess article license } \\
\text { https://creativeco }\end{array}$ & $\begin{array}{l}\text { shed by Siddharth } \mathrm{H} \\
\text { eative Commons Att } \\
\text { licenses/by/4.0/ unp }\end{array}$ & $\begin{array}{l}\text { and Social Welfare Socie } \\
\text { ternational License } \\
4.0] \text {. }\end{array}$ & \\
\hline
\end{tabular}




\section{Introduction}

Acute organophosphorus (OP) pesticide poisoning is widespread and is the most common poisoning in many developing countries and varies in different geographic regions. Accidental and occupational exposures were estimated to cause 1 million cases with 200,000 deaths [1]. Recent data from the National crime bureau of India shows a mortality rateof $26.6 \%(34,869)$ in the year 2017 by the consumption of pesticides. Accidental Intake of Insecticides was reported among 1403 males, 812 females in the age group of $18-30$ years. The majority of suicides were reported in Maharashtra $(17,646)$ followed by 14,459 suicides in Tamil Nadu, 12,014 suicides in West Bengal [2]. Poisoning is the fourth most common cause of mortality in rural India. In North India aluminum phosphide and organophosphate, poison is common. Aluminum phosphide or organophosphate, these substances were developed to control insects and pests and have become major contributors in the causation of poisoning death [3].

Organophosphorus (OP) compounds are used as pesticides, herbicides, and chemical warfare agents in the form of nerve gases. Being predominantly an agricultural country, pesticides and insecticides are used abundantly for cultivation, and access to these poisonous chemical substances by the population is easy [4]. More than 100 different OP compounds have been synthesized. Most of the OP pesticide poisoning and subsequent deaths occur in developing countries following a deliberate selfingestion particularly in young, productive age groups, as highly toxic pesticides are readily available at the moments of stress. The most wellknown are malathion, parathion, fenthion, diazinon, dimethoate, chlorpyrifos, paraoxon, and soman [5].

Organophosphorus compounds are anti acetylcholine sterases which exert their toxicity by interfering with the normal function of acetylcholine, an essential neurotransmitter throughout the autonomic and central nervous system. OP acts by inhibiting the enzyme cholinesterase, results in the accumulation of acetylcholine at synapses and myoneural junction leading to cholinergic overactivity [6]. Patients die mostly from respiratory failure and lung injury, although there is variability in the clinical symptoms and signs depending on the nature of compounds, amount consumed, severity, the time gap between exposure, and presentation in the hospital.
Owing to the limited availability of resources, all OP poisoning patients are not managed in ICUs in the Indian setup. In view of this, a study was conducted to assess the nature of the compound, profile of clinical manifestations, and outcome of organophosphate poisoning presenting to a tertiary care teaching hospital in India.

\section{Materials and Methods}

Setting: Department of General Medicine, Velammal Medical College Hospital and Research Institute, Madurai.

Duration and type of study: A cross-sectional study conducted from January 2016 to July 2019

Sample size calculation: The sample size was calculated assuming the proportion of outcome of OP poisoning as $35.74 \%$ as per the study by Banerjee et al et [7]. The other parameters considered for sample size calculation were $10 \%$ absolute precision and a $95 \%$ confidence level. The required sample size would be 88 . To account for a non-participation rate of about $10 \%$, another 8 , subjects will be added to the sample size. Hence the final required sample size would be 96 which was rounded to 100 participants.

Inclusion criteria: All patients in whom a provisional diagnosis of OPC poisoning was made based on the patient's clinical presentation/history as recorded from the patient's attendant/details of poison containers were included in the study.

Exclusion criteria: Multiple compound/tablet poisoning, contradictory diagnosis regarding the compound, patients with a history of bronchial asthma/cardiac illness or neuromuscular diseases, Patients who died within few minutes of hospitalization even before the initial treatment could be given were excluded from the study.

Data collection procedure: A detailed case history was taken as per the proforma, general physical examination and systemic examination was done soon after admission. Laboratory investigations such as Complete blood count, Random blood sugar, Renal function test, Liver function test, were done at the time of admission. The patients were monitored regularly until the outcome. The diagnosis was made based on history or evidence of exposure to OP compound within 24 hours; characteristic manifestations of OP poisoning include, miosis, fasciculations, excessive salivation, improvement of signs and symptoms with administration of atropine 
Were recorded. It was represented as the muscarinic, nicotinic, and central effects of OP poisoning.

Ethical consideration: Prior approval for the study and the protocol was obtained from the institutional ethical committee.

Statistical analysis: Frequency and descriptive analysis are done using IBM SPSS version 22 statistical software.

\section{Results}

A total of 100 subjects were included in the final analysis.

Table-1: Descriptive analysis of age and gender distribution. $(\mathbf{N}=\mathbf{1 0 0})$

\begin{tabular}{|c|c|}
\hline Parameter & Number $(\%)$ \\
\hline \multicolumn{2}{|l|}{ Age group } \\
\hline$<20$ & $9(9 \%)$ \\
\hline $21-40$ & 66(66\%) \\
\hline $41-60$ & $23(23 \%)$ \\
\hline$>60$ & $2(2 \%)$ \\
\hline \multicolumn{2}{|l|}{ Gender } \\
\hline Male & $80(80 \%)$ \\
\hline Female & $20(20 \%)$ \\
\hline
\end{tabular}

The majority of the subjects were males (80\%) with maximum belonging to the age group of $21-40$ years $(66 \%)$ (Table 1 ).

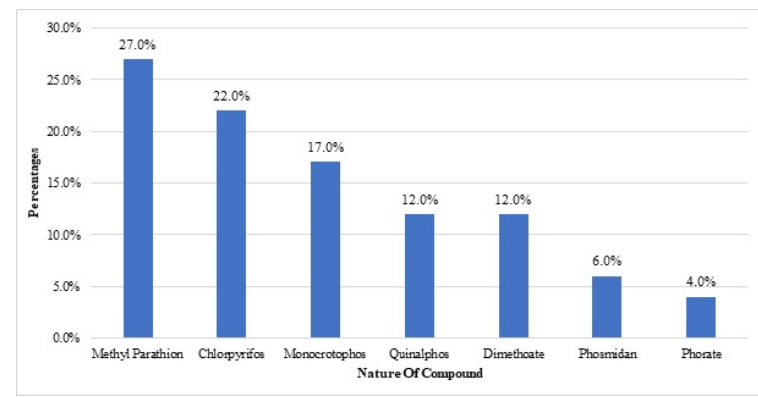

Fig-1: Nature of compound in the study population $(\mathbf{N}=100)$

The most common OPC to be consumed was Methyl parathion $(27 \%)$, followed by Chlorpyrifos (22\%) The least common compound was Phorate (4\%) (Figure 1).

Table-4: Descriptive analysis of clinical presentation in the study population $(\mathrm{N}=100)$

\begin{tabular}{|l|l|l|l|}
\hline \multicolumn{4}{|c|}{ Clinical manifestations } \\
\hline Muscarinic manifestations & Nicotinic manifestations \\
\hline GIT & Number (\%) & Skeletal muscle & Number (\%) \\
\hline
\end{tabular}

\begin{tabular}{|l|l|l|l|}
\hline Nausea and vomiting & $83(83 \%)$ & Fasciculations & $28(28 \%)$ \\
\hline Abdominal pain/cramps & $100(100 \%)$ & Paralysis & $40(40 \%)$ \\
\hline Diarrhea & $18(18 \%)$ & Autonomic nervous system \\
\hline Respiratory system & & Tachycardia & $4(4 \%)$ \\
\hline Oronasal froth & $27(27 \%)$ & Hypertension & $4(4 \%)$ \\
\hline Cyanosis & $8(8 \%)$ & CNS manifestations & \\
\hline Pulmonary edema & $26(26 \%)$ & Altered consciousness & $48(48 \%)$ \\
\hline Cardiovascular system & & Coma & $18(18 \%)$ \\
\hline Bradycardia & $36(36 \%)$ & Intermediate syndrome & $5(5 \%)$ \\
\hline Hypotension & $7(7 \%)$ & OPIDPN & $0(0 \%)$ \\
\hline Eyes & $72(72 \%)$ & & \\
\hline Miosis & $28(28 \%)$ & & \\
\hline Normal pupil & & \\
\hline Exocrine glands & $60(60 \%)$ & & \\
\hline Increased sweating & & & \\
\hline Urinary bladder & $21(21 \%)$ & & \\
\hline Incontinence & & \\
\hline
\end{tabular}

Among the muscarinic manifestation, the major GIT complications were abdominal pain/cramps in $100 \%$, followed by nausea and vomiting in $83 \%$ participants and diarrhea in $18 \%$ participants. Among respiratory system complications, 27 (27\%) participants had Oronasal froth, 26 (26\%) participants had Pulmonary edema and 8 (8\%) participants had Cyanosis. Among cardiovascular complications, $36 \quad(36 \%)$ participants had Bradycardia, and 7 (7\%) participants had hypotension.

$72 \%$ of participants had miosis, $28 \%$ of participants had normal pupil, $60 \%$ of participants had increased sweating and $21 \%$ of participants had urinary bladder incontinence. Among nicotine manifestations, 28 (28\%) participants had fasciculations in skeletal muscle and 40 (40\%) participants had Paralysis. Autonomic nervous system complications, 4 (4\%) participants had tachycardia and hypertension. CNS complications include, 48(48\%) had altered consciousness, 18 $(18 \%)$ had Coma and $5(5 \%)$ had Intermediate syndrome.

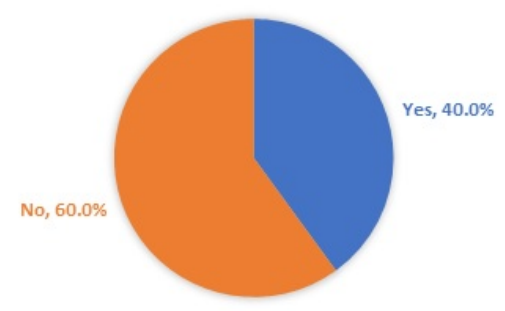

Fig-2: Mechanical ventilation in the study population $(\mathrm{N}=100)$. 
Out of 100 patients included in the current study, 40 $(40 \%)$ required mechanical ventilation (Figure 2 ).

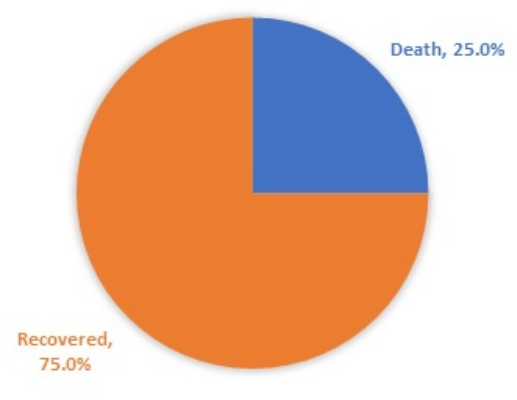

Fig-3: Mortality in the study population $(\mathbf{N}=\mathbf{1 0 0})$.

Out of 100 patients included in the current study, 25 $(25 \%)$ met with mortality, and the remaining 75 $(75 \%)$ of the patients recovered (Figure 3 ).

\section{Discussion}

Organophosphates are frequently used pesticides can result in serious morbidity and mortalitywith over 50,000 organophosphorus compounds have been synthesized since the first one by Clermont in 1857. The clinical symptoms range from the classic cholinergic syndrome to flaccid paralysis and intractable seizures, with mortality ranging from 10 to $22 \%$ [8].

In the present study, two-thirds (66\%) of poisoning cases were in the age group 21-40 years. In the studies conducted by George et al [8], Selvaraj et al [9]. $60-80 \%$ of patients were in the $21-40$ years age group with a peak incidence between 21-30 years. The people in this age group are described to be the most stressful, emotionally weak, and vulnerable to minor conflicts, failures, or disappointments during this phase of life.

The present study showed male predominance in OP poisoning. The incidence of poisoning was higher in males than in females ( $80 \%$ vs $20 \%$ ). The male to female ratio in the present study was $4: 1$. A similar trend was also observed by Padmanaba et al [10] and Joshi et al [11] where the male to female ratio is $1.2: 1$. The reason behind this may be males are the main working group in the outdoor field, i.e. they are more involved in spraying crops in the farms. Methyl parathion was the most common poison consumed (27\%) followed by Chlorpyrifos $(22 \%)$ in this study. Methyl parathion was also
The most common poison detected in the studies of Banerjee et al [7]. Dimethoate was most common in the studies of Banday et al [9]. This variation in the type of poison consumed can be attributed to the regional availability of pesticides in different regions.

Among the muscarinic manifestation, the major GIT complications were abdominal pain/cramps in $100 \%$, followed by nausea and vomiting in $83 \%$ participants and diarrhea in $18 \%$ participants in this study. 27 (27\%) participants had Oronasal froth as a respiratory complication. 36 (36\%) had Bradycardia, $72 \%$ had miosis, $60 \%$ had increased sweating. Among nicotinic manifestations, 28 (28\%) participants had fasciculations in skeletal muscle and 40 (40\%) participants had Paralysis.

CNS complications include, 48(48\%) had altered consciousness.Khan $S$ et al[10]in their study also reported that most common symptoms were excessive salivation (100\%), agitation (87.5\%), disturbances of consciousness (75\%), abdominal pain $(62.5 \%)$ and abdominal cramps (50\%) which was comparable to the present study. Chintale et al[11] reported that excessive salivation was the most common symptom observed (72.05\%) followed by Miosis (71.32\%), fasciculation $(63.23 \%)$, increased bronchiolar secretions $(39.70 \%)$, bradycardia $(57.35 \%)$, neck muscle weakness $(16.91 \%)$ and oronasal frothing (10.29\%).Noshad et al[12] observed Meiosis $(82 \%)$, excessive salivation $(70 \%)$, decreased levels of consciousness (70\%), Agitation (58\%), fasciculation (42\%), Tachycardia (25\%), muscle weakness $(22 \%)$.

In the current study, $40 \%$ of the subjects were on mechanical ventilation. The study was inline withSinghal A et al[13]where $51 \%$ of patients were on mechanical ventilation. The mortality rate in the present study was $25 \%$ and $75 \%$ have recovered from organophosphorus poisoning.Similar results were reported by GV Rao et al, where amortality rate of $27 \%$ was observed [14]. Banerjee et al reported $5.78 \%$ of subjectsdied with respiratory failure being the primary cause of death followed by CNS depression, cardiac arrest, and septicemia [7].

Sungur et al [15] reported a mortality rate of $50 \%$ for the patients who were mechanically ventilated and $21.6 \%$ for the patients who are not mechanically ventilated in their study.Shah et al[16] in their study observed Complete recovery and mortality rate as $66.47 \%$ and $16.47 \%$ among cases respectively. 
A high mortality rate might be due to the greater time taken for admission in the hospital in the present study. Most of the duration from the ingestion of poisoning to initiation of treatment was spent traveling/arranging transport to the hospital. Efforts to minimize the period between ingestion of poison and initiation of specific treatment may help to decrease the chance of death.

The cross-sectional and descriptive nature of the study was the chief limitation, precluding us from performing any hypothesis testing. Assumption of the nature of the compound based on the history and description in few cases would have introduced some bias. Considering the smaller sample size and limited catchment area, the generalizability of the study findings is limited.

\section{Conclusion}

It can be concluded that OP poisoning is more common among the younger population, below 40 years with male preponderance. The majority had a moderate grade of poisoning with a high mortality rate.Timely administration of an antidote insufficient dose and duration are much more important in the patients with evidence of a moderate and severe degree of OP poisoning. Such patients need to be monitored and observed closely with good supportive care. Similarly, strict implementation of the pesticide act and involving a new policy by the government to educate the public and youth in large about the dangerous life-threatening effects of Organophosphorus compounds could help ameliorate the harmful effects of such poisoning.

\section{What does the study add to the existing knowledge}

A high mortality rate was observed with OP poisoning. Measures to be taken to reduce the time taken for admission in the hospital.

\section{Author Contributors}

Dr. Yuri Gagarin has conceptualized the study and played a primary role in compiling analysis, and interpretation of the data. All the drafts were prepared, reviewed and the final draft was approved by Dr. R. Lavanya Rajagopal have contributed tothe fine-tuning of the proposal, contributed to data collection and entry, reviewed the results and contributed to preparation and review of drafts. All the authors have read and approved the final
Version of the manuscript. All the authors take complete responsibility for the content of the manuscript.

\section{Acknowledgments}

Authors acknowledge the technical support in data entry, analysis, and manuscript editing by "Evidencian Research Associates."

\section{Reference}

01. Unnikrishnan B, Singh B, Rajeev A. Trends of acute poisoning in south Karnataka. Kathmandu Univ Med J. 2005;3(2)149-154.

[Crossref]

02. Govt of India. Accidental deaths and suicides in India National Crime Records Bureau Ministry of Home affairs Government of India, National Crime Records Bureau, Ministry of Home affairs. Government of India. 2017. Available at:

[Article] [Crossref]

03. Sharma B, Harish D, Sharma V, Vij K. The epidemiology of poisoning- An Indian view point. J Foren Med Toxicol. 2002;19(2)5-11.

[Crossref]

04. Behere PB, Behere AP. Farmers' suicide in Vidarbha region of Maharashtra state- A myth or reality?. Indian J Psychiatry. 2008;50(2)124-27. doi: [Article] [Crossref]

05. Zawar S. Correlation between plasma cholinesterase levels and clinical severity of acute organophosphate and carbamate poisoning. JAPI. 2001;149;91.

[Crossref]

06. Aygun D, Doganay Z, Altintop L, Guven H, Onar $M$, Deniz $T$, et al. Serum acetylcholinesterase and prognosis of acute organophosphate poisoning. J Toxicol Clin Toxicol. 2002;40(7)903-910. doi: [Article] [Crossref]

07. Banerjee I, Tripathi S, Roy AS. Clinicoepidemiological characteristics of patients presenting with organophosphorus poisoning. $\mathrm{N}$ Am J Med Sci. 2012;4(3)147-150.

doi: [Article] [Crossref]

08. Cherian M, Roshini C, Visalakshi J, Jeyaseelan L, Cherian A. Biochemical and clinical profile after organophosphorus poisoning A placebo controlled trial using pralidoxime. J Assoc Physicians India. 2005;53;427-431.

[Crossref] 
09. Banday TH, Tathineni B, Desai MS, Naik V. Predictors of Morbidity and Mortality in Organophosphorus Poisoning- A Case Study in Rural Hospital in Karnataka, India. N Am J Med Sci. $2015 ; 7(6) 259-265$.

doi: [Article] [Crossref]

10. Khan S, Kumar S, Agrawal S, Bawankule S. Correlation of serum cholinesterase and serum creatine phosphokinase enzymes with the severity and outcome of acute organophosphorus poisoning- study in rural central India. World J Pharmacy Pharmac Sci. 2016;5(4)1365-1373.

doi: [Article] [Crossref]

11. Chintale KN, Patne SV, Chavan SS. Clinical profile of organophosphorus poisoning patients at rural tertiary health care centre. Int J Adv Med. 2016;3(2)268-274.

doi: [Article] [Crossref]

12. Noshad $H$, Ansarin $K$, Ardalan MR, Ghaffari AR, Safa J, Nezami N. Respiratory failure in organophosphate insecticide poisoning. Saudi Med J. 2007;28(3)405-407.

[Crossref]
13. Singhal A, Yang $M$, Sargent $M$, Cochrane D. Does optic nerve sheath diameter on MRI decrease with clinically improved pediatric hydrocephalus?. Child's Nerv Syst. 2012;29(2)269-279.

doi: [Article] [Crossref]

14. Rao GV, Jyothsna M. Relation between Serum Cholinesterase and Mortality among Patients with OP Poisoning. Indian J Clin Anaesth. 2016;3(1)48-51.

[Crossref]

15. Sungur $M$, Guven $M$. Intensive care management of organophosphate insecticide poisoning. Crit Care. 2001;5(4)211-215. doi: [Article] [Crossref]

16. Shah SM, Asari PD, Amin AJ. Clinicoepidemiological profile of patients presenting with acute poisoning. Int J Curr Res Rev. 2016;8(13)35-41.

[Crossref] 